\title{
Editorial
}

\section{Special issue: IMEKO Technical Committee 21 (Part I)}

Dear Reader,

The Technical Committee 21 (TC21) of the International Measurement Confederation (IMEKO) is glad to start this collaboration with the International Journal of Metrology and Quality Engineering with this first Special issue.

The TC21 is an IMEKO initiative intended for bridging the gap between people in universities, research centres and enterprises who are involved in measurements and need advanced mathematical, statistical and computational tools to solve their problems, and to whoever is working in the development of these tools.

The scope of TC21, having presently 30 formal Members and more than 40 Friends in 35 Countries worldwide, is "to promote the harmonisation, the co-ordinated use and the development of new mathematical and statistical tools for measurements, and their implementation in guides, procedures and codes, acting as a portal on an international environment", with the aim "to help advancement

- in research, to bridge the gap between scientists working in the fields of measurement science, metrology, testing, applied mathematics, statistics, databases and IT, allowing better and more efficient tools to be developed for specific purposes. The activities should involve the synergy of specialists in all relevant fields;

- in production and services, by allowing a more efficient transfer of research results to the users in enterprises and a better knowledge of the needs of the enterprises on the relevant issues. The principal scope should be getting more value from the measurements, particularly for the benefit of measurement equipment manufacturers and users who use extensively computational tools;

- by supplementing other IMEKO TCs with a focused viewpoint and activities concerning the development of specific tools in the relevant fields of the scope."

The main event of this Committee, whose website is at http://joomla.imeko.org/index.php/tc21-homepage, is the International Conference "Advanced Mathematical and Computational Tools in Metrology" (AMCTM), also providing input for the book Series with the same name, published by TC21 with World Scientific Publ. Co., Singapore (for the last edition, the 9th, held in 2011, see http://www.worldscientific.com/worldscibooks/10.1142/8432).

This issue is based on the activities of members and friends, and is partially originating from presentations at the XX IMEKO World Congress, held in Busan, Korea in September 2012. Everybody is invited to join our activities.

Franco Pavese, TC21 Chairman

Alistair B. Forbes, TC21 Scientific Secretary

26 October 2012 